\title{
CORRIGENDUM
}

\section{Loss in MCL-1 function sensitizes non-Hodgkin's lymphoma cell lines to the BCL-2-selective inhibitor venetoclax (ABT-199)}

DC Phillips, Y Xiao, LT Lam, E Litvinovich, L Roberts-Rapp, AJ Souers and JD Leverson

Blood Cancer Journal (2016) 6, e403; doi:10.1038/bcj.2016.12; published online 11 March 2016

Correction to: Blood Cancer Journal (2015) 5, e368; doi:10.1038/ bcj.2015.88; published online 13 November 2015

Following the publication of this article, the authors noted the following errors:

1. The final sentence in the legend of Figure 1 should be 'Data are presented as the mean \pm s.e.m. of one-two experiments each in triplicate'.
2. The final sentence in the legend of Figure 3 should be 'Data are presented as the mean \pm s.e.m. of two-three independent experiments'.

3. We inadvertently duplicated a flow cytometry histogram in Figure $5 \mathrm{C}$ (right hand column 5 th row and right hand column 6 th row). This has been corrected in the revised version of Figure 5 as presented below: a
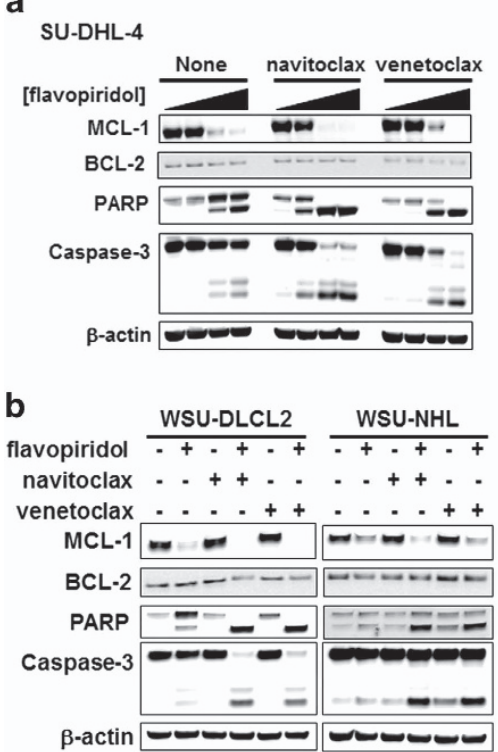

C

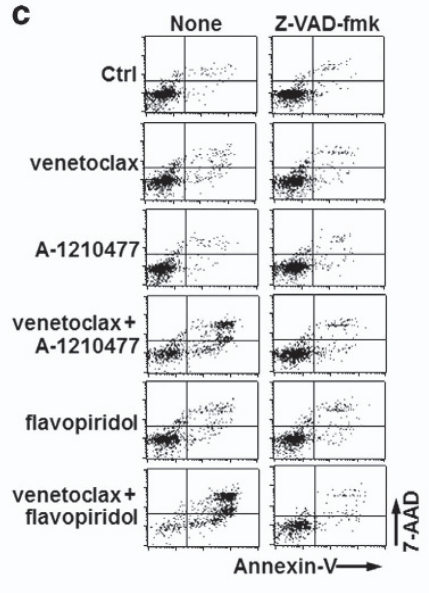

d

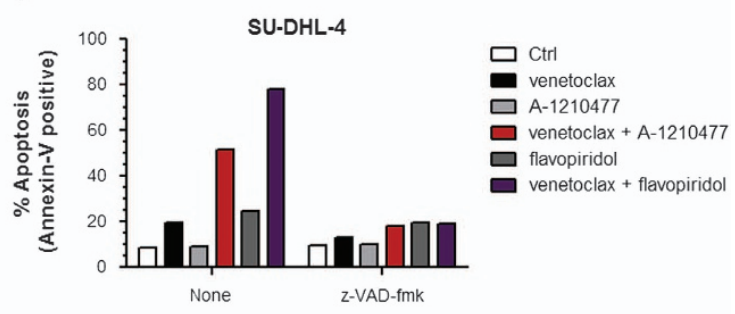

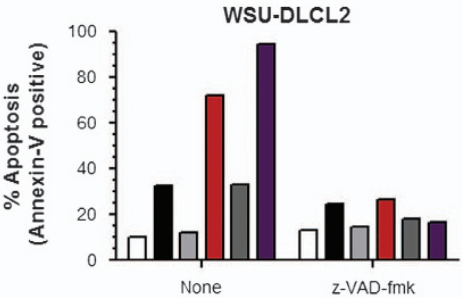

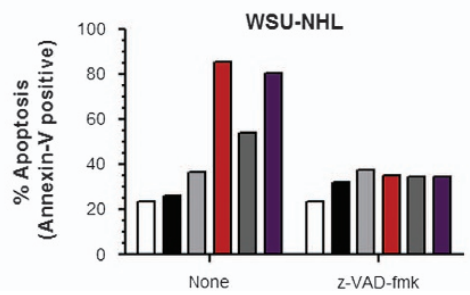

Figure 5. Flavopiridol-mediated downregulation of $M C L-1$ sensitizes $B C L 2^{\text {High }} \mathrm{NHL}$ cell lines to navitoclax and venetoclax in a caspasedependent manner. $B C L 2^{\text {High }} \mathrm{NHL}$ cell lines were co-treated with navitoclax $(1 \mu \mathrm{m})$ or venetoclax $(1 \mu \mathrm{m})$ in combination with flavopiridol at 0 , $16.67,50$ or $150 \mathrm{~nm}$ (a) or $50 \mathrm{~nm}$ (b) for $24 \mathrm{~h}$ before assessing effects on MCL-1, BCL-2, caspase-3, PARP and $\beta$-actin by western blot. Alternatively $B C L 2^{\text {High }}$ cell lines were pre-treated with $\mathrm{z}$-VAD-fmk $(50 \mu \mathrm{m})$ for $1 \mathrm{~h}$ and then co-treated with navitoclax $(1 \mu \mathrm{m})$ or venetoclax $(1 \mu \mathrm{m})$ in combination with A-1210477 $(5 \mu \mathrm{M})$ or flavopiridol $(50 \mathrm{~nm})$ for a further $24 \mathrm{~h}$ and the effect on apoptosis determined by flow cytometric analysis of Annexin-V/7-AAD staining. Representative flow cytometry histograms in SU-DHL-4 cells from three independent experiments are shown in $\mathbf{c}$ and quantified in $\mathbf{d}$. 